University for Business and Technology in Kosovo

UBT Knowledge Center

UBT International Conference

2016 UBT International Conference

Oct 28th, 9:00 AM - Oct 30th, 5:00 PM

\title{
The Implementation of Information Systems in Network Administration: The Improvement of Intranet Utilization in Higher Education Institutions
}

\author{
Besnik Skenderi \\ University for Business and Technology, besnik.skenderi@ubt-uni.net \\ Murat Retkoceri \\ University for Business and Technology, mretkoceri2@ubt-uni.net \\ Rina Sadriu \\ University for Business and Technology, rs347333@ubt-uni.net
}

Follow this and additional works at: https://knowledgecenter.ubt-uni.net/conference

Part of the Databases and Information Systems Commons, and the Information Security Commons

\section{Recommended Citation}

Skenderi, Besnik; Retkoceri, Murat; and Sadriu, Rina, "The Implementation of Information Systems in Network Administration: The Improvement of Intranet Utilization in Higher Education Institutions" (2016). UBT International Conference. 1.

https://knowledgecenter.ubt-uni.net/conference/2016/all-events/1

This Event is brought to you for free and open access by the Publication and Journals at UBT Knowledge Center. It has been accepted for inclusion in UBT International Conference by an authorized administrator of UBT Knowledge Center. For more information, please contact knowledge.center@ubt-uni.net. 
The Implementation of Information Systems in Network Administration: The Improvement of Intranet Utilization in Higher Education Institutions

\title{
The Implementation of Information Systems in Network Administration: The Improvement of Intranet Utilization in Higher Education Institutions
}

\author{
Besnik Skenderi ${ }^{1}$, Murat Retkoceri ${ }^{2}$, Rina Sadriu ${ }^{3}$ \\ UBT - Higher Education Institution, Lagjja Kalabria, 10000 p.n., \\ Prishtine, Kosovo \\ \{besnik.skenderi ${ }^{1}$, mretkoceri ${ }^{2}$, rs $\left.34733^{3}\right\} @$ ubt-uni.net
}

\begin{abstract}
Management Information systems or MIS broadly refers to a Computer system of Information that provides manager the tool to organize, Asses and manage efficiently departments within an organization.

Information System Management serves to assist in the more effective and efficient management of information. These systems make possible the production and preservation.

Nowadays the business, institutions and organization use MIS to certain functions or the entire organization. Some of the most important applicants are in dimensions or functions such as human resources, finance, marketing, manufacturing, asset management etc.

The primary definition shows that the primary task of management information system (MIS. is to process the data of the organization and present them in regular reports in different periods of time depending on the specific requirements of the institution or company.

In this research we have attempted to explore some of most important issues concerning the implementation of IS practices in Network Administration. The case study is focused on the explanation of the function of Intranet in Higher Education Institutions. The research methods used in this research are mix of qualitative and quantitative methods.

The opportunity to improve the functioning of Intranet in these type institutions may be perceived on the better utilizations of resources of the organizations, which in return should lead to more internal functional communication.

In this regard we have analysed the institution resources and we have recommended some organisational change in order to achieve more effective and efficient utilization of resources.
\end{abstract}

Keywords: Information systems, intranet, management, technology,

\section{Introduction}

A Management Information System (MIS) is an information system that is intended to be used by the higher management of an organization. The MIS generally collects summarized data from different departments or subsystems of an organization and presents in a form that is helpful to the management for taking better decisions for the organization. 
On 2007, when for the first time James proposed the goals of intranet, he was explaining it in three parts: Content, Communication and Activity. In 2008, he updates the list and added the section of Corporation in the time when the intranet started to have serious development based on statistics that were given by pages of Internet. Latest he added the section of culture in that time when social intranet become centre of usage into the companies.

Questions addressed in this research:

1. How Intranet does it work?

2. What are the obstacles for Intranet?

3. What are the benefits of using it?

The Implementation of Intranet for an institution is more than a technical project as we are showing in sections below.

Well-projected intranet can realize and perform much more processes into a company or an organization. The communication between workers could be much easier than it was before. It could be very social or perform more different applications integrated in one. Moreover, when new employees get used to work with it they know how to reach each data in a real time effectively without losing any information.

The goal of this research is and to create one inside website as "one-stop-shop" which perform better communication into a organization, institution, faculty etc.

\subsection{The methodology of work}

Even though there are so many researchers done about application of administration of Information systems into domestic organizations and international ones, to arrive in empiric conclusion in this research paper is it used comparative method.

We used to have some different types of Faculties, which Intranet was performed well and it still using with the innovation and latest technology designed.

Main reason why Intranet is not such popular in administration section in our organizations and so are:

$>$ There is no information detailed about information technology in whole market,

$>$ Unsuitability between employees and new information technology in new development or progress into a company

$>$ The high cost of information does not require with the income of companies

$>$ Problems with publishing processes

Analysis and successful utilisation of data sets can find new correlations to business processes, business trends and can lead to innovations.

\subsection{The improvement of intranet}

To work easily latest, the University of Graz has launched a new intranet to collaborate in efficiency and research new data into a company.

Situation: the Graz University its one of the second oldest faculty in Austria it is known university all around the world. More over it doesn't have any intranet before in their faculty, so the employee doesn't have the information when they needed they used to have hard copy in their hands and share it as a linked document by FTB. All the employees have the difficulty in all processes then they thought that we need something that our employees will thank us one day.

Present situation: 
The Implementation of Information Systems in Network Administration: The Improvement of Intranet Utilization in Higher Education Institutions

Changes in technology and business are happening so fast that the world seems in constant chaos. Our traditional theories of management and organization seem less and less capable of pointing us to useful courses of action.

Benefits:

With their new intranet, University of Graz employees now have one central place to share documents and expertise. Thanks to SharePoint 2013, our employees can get to information within minutes whereas before they might search for days.

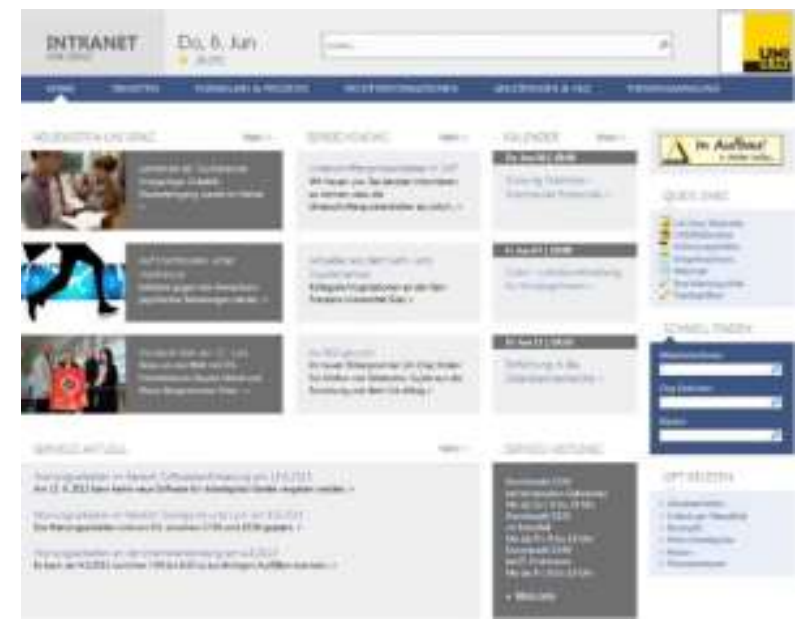

Figure 1 Example of Intranet

\section{The-State-Of-Art Of University Of Sydney From Shutterstock}

The key to success was a targeted project plan, a disciplined approach, and excellent stakeholder engagement. Over the past decade, a number of universities have attempted to create an intranet, but many have failed.

As a result of a university-wide web strategy, a project was initiated at Sydney University to create the first true staff intranet.

Within a week of the originally planned go-live date, the team delivered:

- A new staff intranet for all 10,000 staff across the university.

- A new site structure (information architecture) that was tested extensively with staff.

- Substantially improved and simplified content, through the use of professional writers.

- Support for mobile devices, using a responsive web design (RWD) template.

- Decommissioning of old websites, thereby simplifying the main website for all other users.

- A launch and engagement plan, including an online interactive tour for new users. 


\subsection{Present progress:}

The project team attributes their success to a number of key factors, including:

- Conducting robust planning at the outset of the project, to develop a clear scope and approach.

- Ensuring alignment within the team and key stakeholders to a clear overall vision.

- Reducing the potential size of the project, to target key deliverables that would position the intranet for further enhancements after the initial go-live.

- Segmenting the project into multiple streams that could operate in parallel.

- Breaking down the activities into independent 'segments' that could be adjusted or rescheduled, giving the project much-needed flexibility.

- Proactively and extensively engaging stakeholders across the university, building support for the approach and outcomes.

- Following a best-practice UX methodology that used task-based testing with staff to ensure that the new site would be usable and valuable.

Evaluating the role and effectiveness of an intranet in facilitating knowledge management: a case study at Surrey Country Council- UK

The research study discussed here examined the role and effectiveness of intranet technology in the process of creating and managing knowledge for the Social Services Department of Surrey County Council, which is one of the largest local authorities in the UK. Based on an analysis of the literature in the field, we devised an intranet evaluation model (IEM) using both technical (hard) and human (soft) factors. It made use of an epistemological framework to elicit user mental models from across an organisation via a survey.

The model was able to identify gaps, mismatches and failings in the knowledge management efforts. These were summarised in an easily understandable diagrammatic form, using knowledge evaluation maps; these showed the gap between the current and desired intranet roles for the different user groups within the council.

The paper concludes by demonstrating how factors, such as the different mental models of the user groups can determine the effectiveness (or otherwise) of an intranet in managing organisational knowledge. It also contains recommendations of services that need attention in the council operations and suggests how the IEM could be used as a consulting tool for organisations seeking to evaluate their own knowledge management work on a continuous basis.

\section{The implementation of intranet}

The needs on search on intranet are huge. It is estimated that intranets at enterprises have tens or even hundreds of times larger data collections (both structured and unstructured) than Internet. In addition with implementation of Share Point as online platform intranet can be used by all staff.

The most preferred and user friendly tool for online collaborating is SharePoint. Gatewood (2009) states that, "Microsoft SharePoint is becoming ubiquitous" (p.33), and he predicts that SharePoint will become part of every company. 
The Implementation of Information Systems in Network Administration: The Improvement of Intranet Utilization in Higher Education Institutions

SharePoint enables online storage of documents, through document libraries, (Setser, 2012) and project team members and project managers save time when they search for information (Bates and Smith, 2010; Skenderi, 2013).

Figure 1 shows an example of a SharePoint team site, where each team has its own site where documents, issues and tasks can be read and updated by project team members.

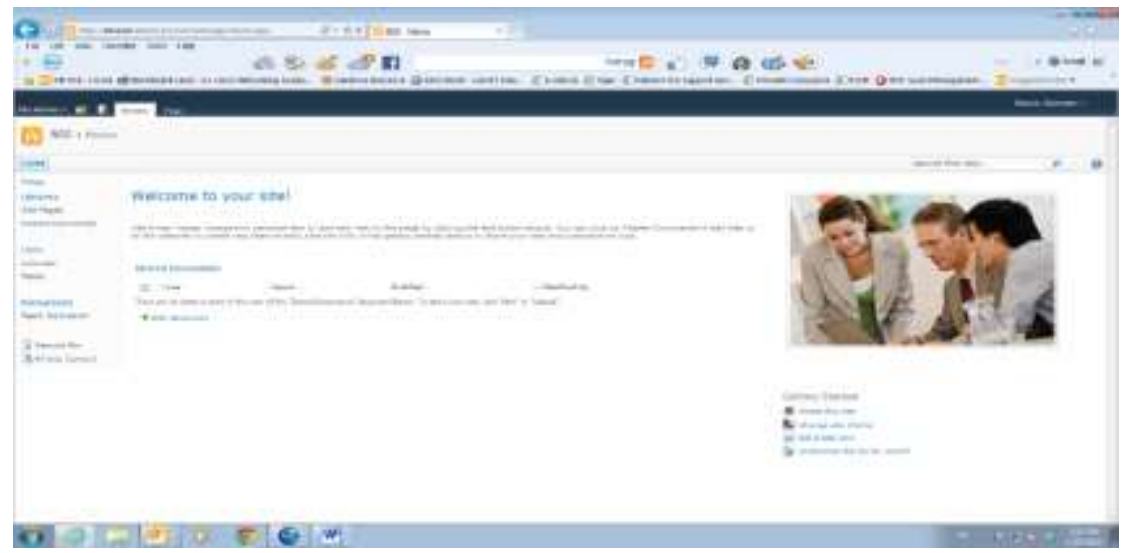

Figure 2 Example of SharePoint Team Site

Doane (2010) in his research concludedes that companies are paying 16,990 USD per year for one worker's time spent searching for information, and with proper implementation of SharePoint this cost could be reduced.

In addition, with SharePoint implementation, project managers will have more time to focus on project issues, rather than communicating with project team members, since according to Piyush, Dangayach, and Mittal, (2011), "about $88 \%$ of project managers spend more than half of their working time interacting with others" (p.50). Moreover, SharePoint offers the possibility for online approval of documents and requests. Examples of approval and rejection are shown in Figure 3. 
Book of Proceedings

International Conference on Information Systems and Security

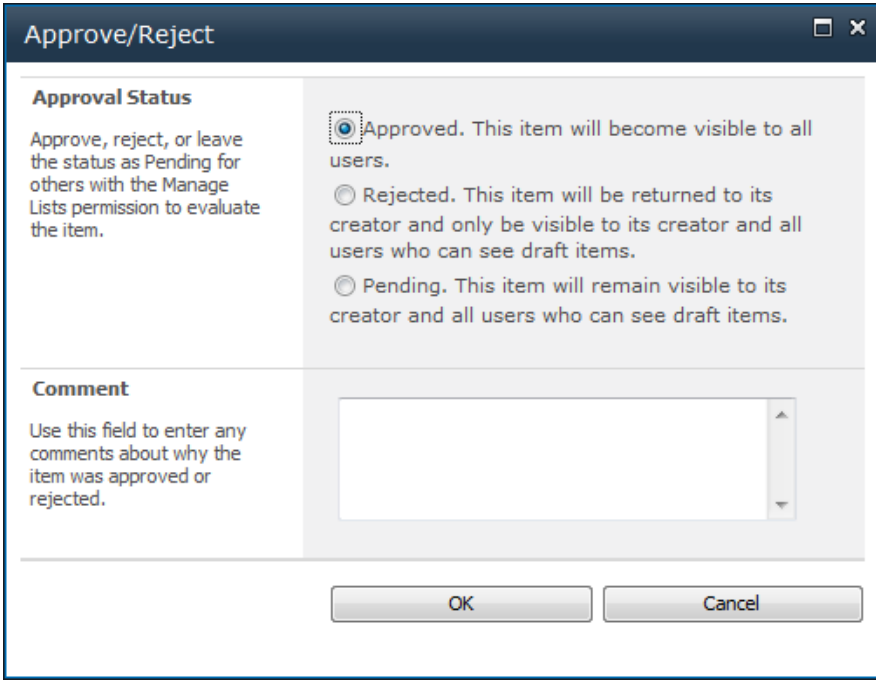

Figure 3, Approve / Reject Dialog Window in SharePoint

\section{Conclusions}

In conclusion, intranet technology is a complex tool kit of innovative ideas that must be customdesigned for each organization, institution or a company. This research paper presents the findings from few different intranet-using faculties, with the aim of exposing some of the issues being confronted across different faculties or institution around the world.

These reviews also show that even within seemingly similar organisations, the intranet issues can be quite different.

This highlights that there is no 'one size fits all' intranet solution, and emphasises the value of conducting meaningful 'needs analysis' activities, such as those outlined in this article.

Technological innovation has altered project management as a business discipline and the role of the IT department in an organization. Based on the findings from the actual research, it is concluded that IT is taking a leading role in business organizations. This happens as business units don't have the skills to use the latest technology and don't know which kind of services to request from the IT department. Based on these findings, it is also recommended that further research be undertaken regarding the role of IT departments in the current business environment and thus to identify whether the IT department is shifting from a support unit into a business strategic unit. 
The Implementation of Information Systems in Network Administration: The Improvement of Intranet Utilization in Higher Education Institutions

\section{References:}

1. Bates, S., Smith, T. (2010). SharePoint 2010 User Guide. John Wiley \& Sons, Inc.

2. Gatewood, B. (2009). Selecting the right tools for records management. Information Management Journal, 43(1), 33-37.

3. http://www.steptwo.com.au/papers/case-study-university-sydney/

4. Setser, B. (2012). For new dimensions of business intelligence and communication. Journal Of Property Management, 77(5), 23.

5. Skenderi, B. (2013). Udherefyes per Share Point. BSS. 